\title{
Integrated assessment of future water security: the case of Makassar, Indonesia
}

\author{
$\underline{\text { L. Neumann }}^{\text {a }}$, G. Tjandraatmadja ${ }^{\text {a }}$, D. Kirono ${ }^{\text {b }}$, M. Selitung ${ }^{\text {c }}$ \\ a CSIRO Land and Water, Highett, Victoria; b CSIRO Marine and Atmospheric Science, Aspendale, Victoria, \\ cUniversity Hasanuddin, Makassar, Indonesia, \\ Email: luis.neumann@csiro.au
}

\begin{abstract}
In many urban areas, population growth and changes associated with climate change are likely to increase pressure on water resources. One such location is Makassar City, located in South Sulawesi, Indonesia, which is experiencing rapid growth, urban sprawling and an increase in freshwater demand but faces a possible reduction in water availability due to climate change.
\end{abstract}

A study, as part of the CSIRO-AusAID Research for Development Alliance, combined climate change, hydrological and resource allocation modelling to examine water security and the resilience of planned infrastructure to climate change impacts. Rainfall and potential evapotranspiration from 5 different Global Circulation Models (GCMs) were statistically downscaled using the CSIRO Conformal Cubic Atmospheric Model, CCAM (McGregor and Dix, 2008). The downscaled rainfall and potential evapotranspiration were used in a hydrological model (SIMHYD) to estimate changes in streamflow for the two rivers which supply Makassar City.

As shown in Figure 1 (right), although the CCAM projections show a reasonable variation for the projections of streamflow for both the Maros and Jennebarang catchments, all CCAM based projections of future streamflow agree on a reduction compared to historical records. The future predictions of streamflow indicate a reduction of mean annual streamflow in the order of $0-25 \%$, with reductions in the mean wet season flow of the same order when compared to the period 1980-1999. The reductions in streamflow for the dry season are projected to be between $5-35 \%$.
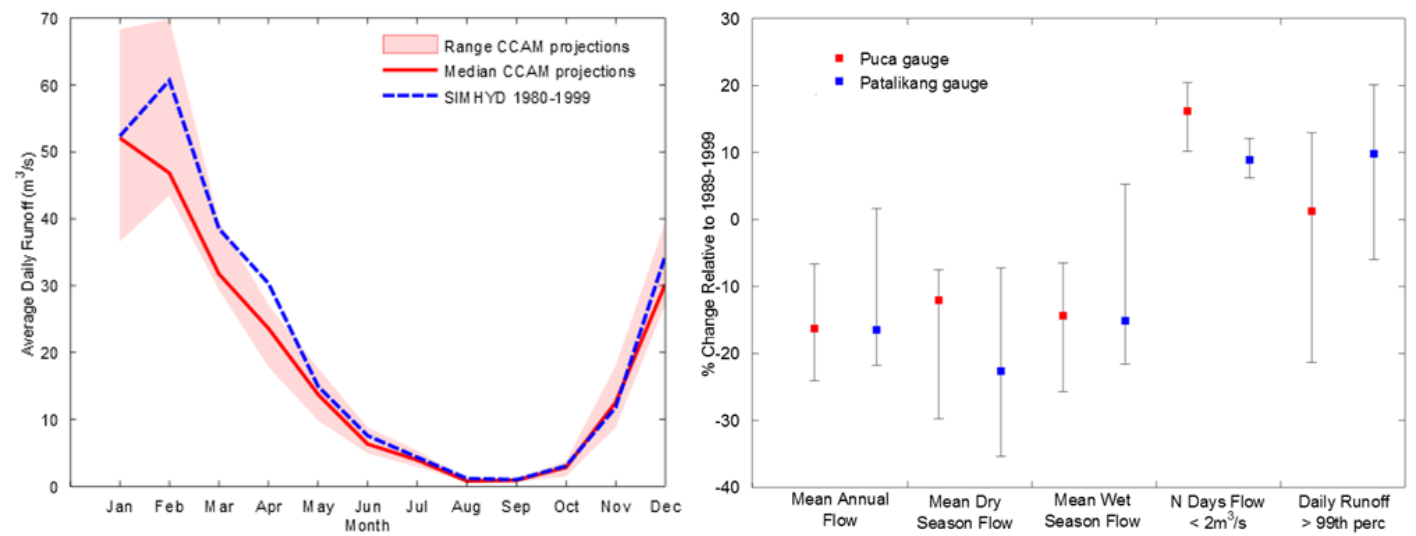

Figure 1. Predicted average daily runoff for the Puca gauge for the period 2020-2040 (left) and percent changes for mean annual, dry and wet season, number of days with flow below $2 \mathrm{~m}^{3} / \mathrm{s}$ and $99^{\text {th }}$ flow percentile for the periods 2020-2040 (right) at the Puca (red symbols) and Patalikang gauges (blue symbols).

The streamflow projections were combined with population projections, infrastructure development plans and water demand estimates to assess future scenarios of water supply capacity for the city, using the REsource ALlocation Model (REALM) software. Results indicate that under the assumed scenarios sufficient inflow for urban water allocation alone will be available during the wet season. However, during the dry season Makassar is likely to face supply problems not only due to reduction in streamflows, but mainly due to infrastructure constraints, population growth and competing water uses. The analysis suggests that the future water security in Makassar will depend on its ability to plan infrastructure and manage water demand despite of climate change. The information generated in this study has allowed key stakeholders to gain greater insight into the future water resource pressures and to re-assess adaptation options.

Keywords: Hydrological Modelling, Integrated Assessment, Water Resources Allocation, Climate Change 


\section{INTRODUCTION}

Climate change is likely to change the patterns of rainfall, evapotranspiration and other climatic variables in different regions. There have been several hydrological modelling studies across the world to estimate the impact of these changes on runoff and water resources (Chiew et al., 2010; Bennett et al., 2012). These studies usually consist of a sequence of steps, first of which is choosing one or more Global Circulation Models (GCMs) and climate change scenarios. The GCM projections are then downscaled to an appropriate scale using various statistical methods or dynamical regional climate models (Chiew et al., 2010). Finally, the downscaled projections are used as inputs to one or more hydrological models and impacts are evaluated by comparing the current and future scenarios. All of these steps impart different levels of uncertainty on the results of climate change impacts on runoff, but several studies found that the GCMs are the highest source of uncertainty (Kay et al., 2009 ; Chiew et al., 2010).

Streamflows generated by the hydrological models can then be used in water resource planning, which uses simulation and/or optimization models to examine the behaviour of complex water supply environments by combining streamflows, water infrastructure characteristics, operation rules, water demand and climate. (Perera and James, 2003; Yates et al., 2005). Traditionally, water utilities adopt long-term historical records of precipitation and temperature to simulate and predict future streamflows and water storages (Thoms and Sheldon, 2000), however given the likely change in rainfall due to climate change, the use of climate averages based historical records no longer may be appropriate. In fact, uncertainties in population and water demand may have a higher impact for water security than uncertainties in GCMs (Paton et al., 2013).

Makassar City, Indonesia, depends on seasonal rivers for water supply. Its water supply Masterplan aims to augment the city's water supply infrastructure to cater for its growing population needs (CSIRO, 2012). However despite its vulnerability to seasonality, climate change and its potential impact on water security have not been considered in the Masterplan development due to lack of future climate data. This paper presents the results of a study on the resilience of Makassar's future water infrastructure to climate change and urban growth. The study used an integrated assessment based on climate downscaled projections of rainfall and runoff, hydrological modelling and supply demand balance to investigate changes to urban supply availability due to climate change and infrastructure projects.

\section{DESCRIPTION OF STUDY AREA}

Makassar is the capital city of the South Sulawesi Province, located in Eastern Indonesia. The city, located on the west coast of the island, has an area of around $176 \mathrm{~km}^{2}$ and hosted 1.27 million inhabitants in 2009 (BPS, 2010), but is expected to increase $20 \%$ by 2020 (CSIRO, 2012). The climate is warm and tropical with rainfall dominated by the Asian monsoon, with a distinct wet season (northwest monsoon) in NovemberApril, and dry season (southeast monsoon) in May-October.

Three rivers (i.e. Jennebarang, Tallo and Maros) are important for the water supply and drainage of Makassar city. The Maros and the Jennebarang rivers are the main raw water sources for Makassar city and also for other cities in the region. Around 80 percent of the current water supply to the city is provided by the Jennebarang River through the Bili-Bili dam (Tjandraatmadja et al., 2012). The Makassar municipal water company (PDAM) treats the surface water from the Maros and Jennebarang Rivers to supply around $63 \%$ of the population, with the partial coverage partially due $30 \%$ water losses in the distribution network (Nihon Suido Consultants Co. LTD. et al., 2011). Surface water resource availability is very sensitive to the occurrence of droughts particularly from the Maros River, as one of the intake pipes for water capture cannot access water when flow rates in the Maros are below a minimum threshold of $2 \mathrm{~m}^{3} / \mathrm{s}$ (Nihon Suido Consultants Co. LTD. et al., 2011). To meet an expected rise in future demand, the city Masterplan details plans to upgrade the urban water system to meet at least $90 \%$ of the urban demand and supply $85 \%$ of the population by 2025 .

\section{METHODOLOGY}

\subsection{Modelled point rainfall}

The hydrological model used in this study requires two inputs: daily rainfall and potential evapotranspiration at a point scale. Future climate projections were obtained by dynamically downscaling five IPCC-CMIP3 GCM data sets using the CSIRO Conformal Cubic Atmospheric Model, CCAM (McGregor and Dix, 2008). The five GCMs are GFDLM2.1, MIROC Medres, CSIRO Mk3.5, MPI Echam 5, and UKMO HadCM3 which were forced by the SRES-A2 emission scenario, as current emission levels are at or above those specified by this scenario and therefore it appears to be realistic (Leggett and Logan, 2008). The regional 
climate simulations (hereinafter referred as CCAM) have a resolution of around $14 \mathrm{~km}$ by $14 \mathrm{~km}$ per grid cell for the period 1971-2100. The future point rainfall was estimated using the gridded CCAM future projections of rainfall and the 'daily translation method', also known as 'bias correction' (see for instance Bennet et al. (2012) for details). In this method, a 'quantile-quantile' distribution mapping technique was used to establish a relationship between the observed point daily rainfall (1971-2010) and the CCAM historical daily data (1971-2010). This relationship is then used to translate the CCAM future daily historical rainfall series to obtain a point future daily series.

\subsection{Model setup}

The lumped daily rainfall-runoff model SIMHYD (Chiew et al., 2002) was used to estimate streamflows. SIMHYD is a daily model with a relatively simple representation of the hydrological processes using 7 parameters and which has been used extensively in climate change studies (Chiew et al., 2010; Bennett et al., 2012). The hydrological modelling also included catchment routing using two linear storages as in the PDM model (Moore, 2007), while the channel routing uses a linear storage model, adding another 3 parameters to the calibration. SIMHYD and the routing models were implemented within the SWIFT modelling system (Pagano et al., 2012). There are three streamflow gauging stations (Patalikang, Puca and Bantimurung) located in the study area, but data quality prevented the use of the Bantimurung station data. Therefore the hydrological models were calibrated for the Puca (Maros River) and Patalikang (Jennebarang) gauges. During calibration, model parameters for both hydrological models and calibration periods were optimised using the Shuffled Complex Evolution (Duan et al., 1993) global optimisation method to maximise the Nash and Sutcliffe (1970) efficiency (NSE). A NSE of 1 indicates a perfect model fit, while a value of zero suggests the mean of the observations is a better predictor than the model.

The bulk water supply and demand for Makassar was modelled using the REsource ALlocation and Model (REALM) software using monthly time steps. REALM models the bulk water supply and distribution for a network of demand, supply centres and carriers, and optimises the water balance at selected time steps using a linear network algorithm to allow the investigation of alternative scenarios (Perera and James, 2003). The focus was on the urban areas, and therefore agricultural demands were not evaluated and only used as a reference for comparison in the analysis (CSIRO et al, 2012).

\subsection{Model simulations}

The optimised hydrological models were used to simulate runoff over two future climate 20 year periods, once period centred around 2030 and one centred around 2050, using CCAM downscaled rainfall and evapotranspiration. The future streamflow estimations were then compared to the streamflows based on historical rainfall to estimate changes due to climate change. The future streamflow predictions were then used in REALM in order to estimate the capacity of the bulk water supply infrastructure to meet the demand in Makassar for 2020-2039. REALM was only used for the first period as population and infrastructure plans were unavailable for the second period.

The REALM model scenarios included three different streamflow estimations: a business as usual case using historical streamflows; and two CCAM based projections, representing the smallest (MK 3.5) and the largest change (MIROC Medres) in streamflows. The future scenarios investigated the impact of climate change and planned infrastructure upgrades, including water supply infrastructure capacity, leakage reduction in distribution and rezoning of water service zones as per the city Masterplan. It is important to note that the capacity to achieve the targets set in the Masterplan is linked to access to Indonesian and donor agencies' funding. The model considers the water extraction system from the Jennebarang and the Maros rivers that supply the five major Water Treatment Plants (WTP) in Makassar (WTP 1, 2, 3, 4 and 5), all assumed to operate at full design capacity. As shown in Table 1, WTP4 can extract water from both the Maros and Jennebarang rivers, with the former being the preferential supply despite relative high losses in the supply channel (Lekonpancing canal) to Lekonpancing weir, with the latter used in case of low water levels in the Maros river. Five other treatment plants provide water to the provinces of Gowa and Maros but as the study focus is Makassar city, their demand was combined and represented by a single node (Table 1). Demand nodes for each treatment plant were estimated based on the service zones, the population projections for each area and the water usage patterns.

Future population figures were estimated by extrapolating the average annual growth for 2008-2010 (BPS, 2010 ) in each of the city sub-districts, with new areas undergoing more rapid growth than established areas. Changes to demand per capita, infrastructure and water distribution coverage were assumed to follow those outlined in the Masterplan (Nihon Suido Consultants Co. LTD. et al., 2011): 
- water demand: 117 liters/person/day (up to 2014), 140 (2015), 165 (2020) and 190 (2025);

- $\quad$ service coverage area: $72 \%$ (2010), $76 \%$ (2015), $81 \%$ (2020, 85\% (2025);

- distribution losses: $30 \%$ (2010), $25 \%$ (2015), $20 \%$ (2020) and $15 \%$ (2025).

Throughout the simulation, industrial water demand was assumed to maintain the same ratio to residential water supply as in 2010 , while demand was assumed to be $10 \%$ higher in the dry season based on billing data (Tjandraatmadja et al, 2012). REALM runs were checked for mass conservation and to avoid model instabilities, low convergence criteria were adopted for storages $(0.3 \%)$ but not for pipe carriers $(10 \%)$.

Table 1.Water treatment plant capacities in Makassar (Tjandraatmadja et al., 2012)

\begin{tabular}{|c|c|c|c|c|c|c|}
\hline \multirow{2}{*}{$\begin{array}{l}\text { Production } \\
\text { capacity } \\
\text { (ML/month) }\end{array}$} & \multicolumn{5}{|c|}{ Water treatment plant (WTP) } & \multirow[b]{2}{*}{ Other provinces } \\
\hline & 1 & 2 & 3 & 4 & 5 & \\
\hline 2010 & 131 & 328 & 526 & 2891 & 2628 & 901 \\
\hline 2020 & 131 & 328 & 526 & 3154 & 7884 & 3992 \\
\hline Intake Point & Jennebarang & Maros & Jennebarang & Maros/Jennebarang & Jennebarang & Maros/Jennebarang \\
\hline
\end{tabular}

\section{RESULTS}

Overall, the downscaled rainfall projections for the historical period and gauged values are very similar, although all models seem to overestimate the rainfall for the period November-January (not shown). Projected changes in rainfall characteristics for the future periods relative to the historical record suggest a reduction in mean daily rainfall for most of the year, with the exception of the month of May. Across all models, the potential evapotranspiration is set to increase by around $12 \%$ (not shown).

\subsection{Calibration and validation for the historical period}

The results for the calibration and validation of the hydrological modelling can be considered satisfactory, with NSE values in the Puca gauge (Maros catchment) of $0.66 / 0.56$ (calibration/validation), while at the Patalikang (Jennebarang catchment) gauge, the performance is somewhat poorer, with NSE values of $0.51 / 0.47$ (calibration/validation). The performance of SIMHYD in simulating mean historical flows is shown in Figure 2 (blue dashed line). The SIMHYD simulations show a good performance for most of the year, with the exception of February where it overestimates the mean flow, and for the wet period between May to August where it under predicts the mean flow. Figure 2 also shows that the quantile corrected CCAM rainfall and potential evapotranspiration are capable of simulating the historical streamflows, with the overestimation of streamflows in the period NovemberFebruary being in line with the overestimation of rainfall as discussed above. The CCAM based simulations also seem to underestimate streamflows in the dry season.

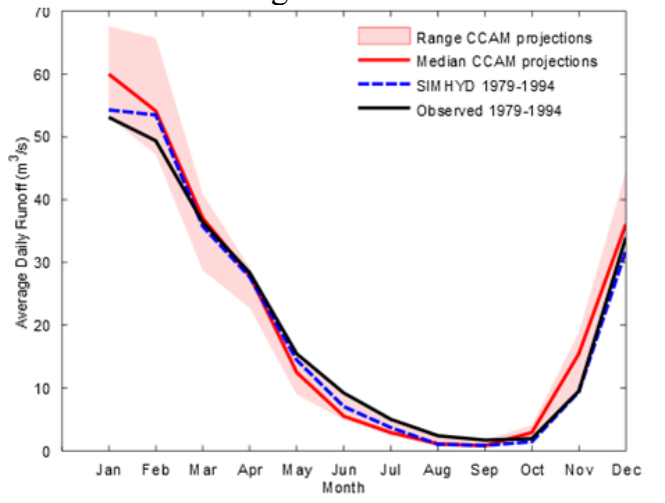

\subsection{Projected changes in streamflow}

The optimised SIMHYD parameter values from the hydrological model calibrations shown in the previous section were used to simulate streamflows for the Maros and Jennebarang catchments. Streamflow projections for Puca gauge in the period 2020-2040 are

Figure 2. Average daily runoff at the Puca gauge in the Maros catchment. (- - gauged historical flows, --- SIMHYD runoff for historical period, - Median and range of historical SIMHYD streamflows using CCAM simulated historical rainfall shown in Figure 1 (left) as well as streamflow simulations for the period 1980-1999 (using historical rainfall). The streamflow projections shown in Figure 1 (left) suggest that for the period January-February, the CCAM based simulations show a large variability, but for the remainder of the year the uncertainty is reduced. In general, compared to historical streamflows, the median of the CCAM projections shows a reduction in streamflows for most of the wet season as well as for the dry season. Similar trends occurred in the Jennebarang (not shown). According to Figure 1 (right), the projected changes in streamflows statistics for both the Jennebarang and Maros catchment at the gauge sites is very similar, with reductions in mean streamflows throughout the year, with an increase for the number of days of extreme runoff ( $>99$ th percentile) and in the number of days with flow below $2 \mathrm{~m}^{3} / \mathrm{s}$ which presents problems for water capture in the Maros catchment. For both catchments, most of the CCAM projections show a similar trend, with 
significant disagreements only on the extreme runoff for the Maros gauge where some CCAM projections show a decrease in extreme runoff.

\subsection{Water supply and demand forecasts}

The historical and CCAM based streamflows were used in REALM to assess the water supply and demand balance and to calculate the Normalized Deficit (ND), defined as the sum of the inflows into water storages (Lekonpancing weir and Bili-Bili dam) minus the sum of the water demands from the treatment plants, divided by the 10 year average historical inflows into the water storages. The calculated deficits are shown in Figure 3, where the ND (peak) values are positive throughout the wet season as inflows to the Lekonpancing weir and the Bili-Bili dam can satisfy urban demands without drawing out on the existing storages. In the dry season water reserves are strained with ND values close to or below zero, and therefore demands may not be met. If current (year 2010) irrigation demands are considered, the water deficit will increase over time particularly in the dry season resulting in severe draw down of storages (not shown). It is also clear from Figure 3 that both climate change scenarios using Mk 3.5 and MIROC Medres estimate increased variability and larger seasonal fluctuations in the ND. For both climate change scenarios, representing the smallest and largest estimation in inflow reduction, the water deficit increases in comparison to the historical inflows during most years. Due to the lack of storage and increased demand, shortages in the Lekopancing weir become more frequent, while the overall system becomes more dependent on Bili-Bili dam to meet demand (not shown).

Although flow reductions due to climate change can be expected for both wet and dry seasons, the most significant impact on the future water supply capacity is likely to be due to planned infrastructure upgrades as shown in Figure 4. As shown in detail for WTP4 in Figure

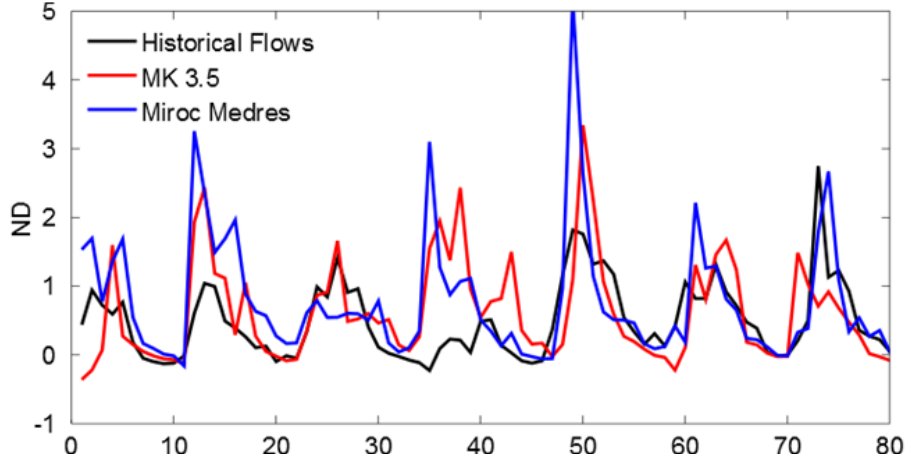

Figure 3. Normalized deficit for different months using historical streamflows and streamflows based on MK 3.5 and MIROC Medres projections

4 (left panel), and for all other treatment plants (Figure 4, right panel), the performance of the water treatment plants is very similar irrespective of the climate change scenario. Over $80 \%$ of the future water demand in Makassar will be met by the five largest treatment plants after the infrastructure upgrades outlined in the city's Masterplan, with the capacity of the different WTPs to meet demand being limited by production capacity not climate change. In particular, WTP4 will only be able to meet just over $40 \%$ of its annual demand due to seasonality constraints that limit capture in the dry season.
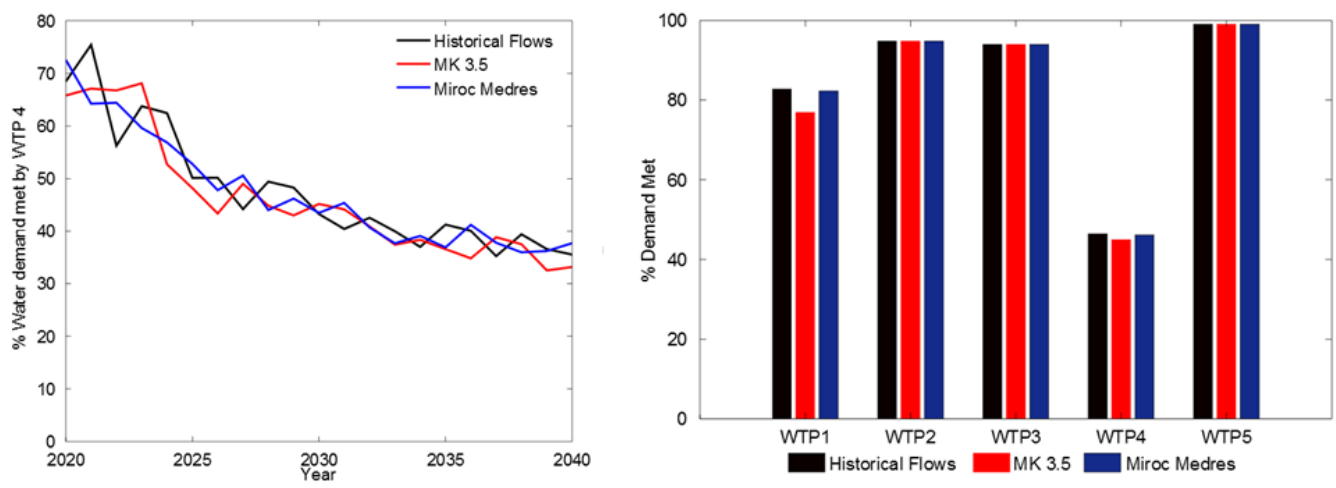

Figure 4. Comparison of the demand supplied by WTP4 under different climate scenarios (left) between 2020-2040, and average across the period for all plants (right).

\section{DISCUSSION}

The results presented in the previous sections show that realistic streamflow can be reproduced using CCAM downscaled rainfall that have been corrected using quantile-quantile mapping, as noted in other studies (Bennett et al., 2012). Although the CCAM projections show a reasonable variation for the projections of streamflow for both the Maros and Jennebarang catchments, all CCAM based projections of future 
streamflow agree on a reduction of streamflows compared to historical records. Based on the median of the CCAM projections, the future predictions of streamflow indicate a reduction of mean annual streamflow in the order of $0-25 \%$, with reductions in the mean wet season flow of the same order when compared to the period 1980-1999. The reductions in streamflow for the dry season are projected to be higher, between 5$35 \%$, while the number of days with flow below the $2 \mathrm{~m}^{3} / \mathrm{s}$ is likely to increase by $8-25 \%$. All CCAM projections also indicate an increase in the number of days in the dry season in which streamflows are below the minimum threshold for capture at Lekopancing canal, and in this case the difference between projections is small. This reduction poses a significant threat to the water supply in the northern part of Makassar City as it will be supplied by WTP4 which take water mostly from the Lekopancing. While the reduction in flow during the wet season is significant, the integrated assessment of water security using REALM shows that it is not likely to be the biggest impact for the future water supply in Makassar alone.

Results indicate that under the assumed scenarios sufficient inflow for urban water allocation alone will be available during the wet season. However, during the dry season urban Makassar is likely to face supply problems not only due to reduction in streamflows, but mainly due to infrastructure constraints, population growth and other water uses such as irrigation. Thus, despite upgrades in infrastructure planned in the city's Masterplan, seasonality will continue to impact water supply for treatment plants dependent on the Maros River. The analysis suggests that the future water security in Makassar will depend more on its ability to manage infrastructure condition than on streamflows changes due to climate change. The Masterplan assumes large investment in water supply and distribution infrastructure to reduce leakage from $30 \%$ to $15 \%$, increase in water extraction and treatment capacity across the region, and also assumes increase in per capita water demand. Therefore if the Masterplan is not implemented the water supply capacity may not keep pace with demand and exacerbate the problem posed by streamflow reductions in a shorter time frame. Therefore, as found in other studies (Paton et al., 2013), uncertainties in relation to demand and population growth are more significant in Makassar than the uncertainties associated with GCMs.

The results shown need to be considered in the context of the model assumptions and its limitations. While the demands adopted in this study are fairly conservative, being almost $50 \%$ larger than current demands, they do represent Indonesia's national average and the expectation that Makassar's consumption is growing and is expected to reach Indonesia's average by 2030 (Tjandraatmadja et al., 2012). Therefore, demand management will be an important tool to help the local utility to meet its supply targets during the dry season as demonstrated in a number of countries such as Australia (Mitchell, 2006). Also, the role of alternative sources including groundwater has not been considered in the analysis due to data scarcity, although it is an important water source for water users in Makassar. Stakeholder reports suggest higher mains water consumption in the dry season compared to wet season due to drying of shallow wells (Tjandraatmadja et al., 2012), so groundwater availability and its impact on the $10 \%$ increase in demand assumed here should be considered in future refinements of the model as data becomes available. Other issues that may warrant further exploration are related to Bili-Bili dam capacity. There is anecdotal evidence that the storage capacity of Bili-Bili dam is lower than the design capacity adopted here due to the sedimentation episodes observed in recent years, since the collapse of Mount Bawakaerang, however no verification data exists at present (Selintung, 2000), this may further reduce the reliability of water supply.

\section{CONCLUSIONS}

A study, as part of the CSIRO-AusAID Research for Development Alliance, has used a combination of climate change, hydrological and resource allocation modelling to examine the resilience of planned infrastructure to climate change impacts. Although the CCAM projections show a reasonable variation for the projections of streamflow for both the Maros and Jennebarang catchments, all CCAM based projections of future streamflow agree on a reduction compared to historical records. Based on the median of the CCAM projections, the future predictions of streamflow indicate a reduction of mean annual streamflow in the order of $0-25 \%$, with reductions in the mean wet season flow of the same order when compared to the period 1980-1999.

Despite all climate projections showing a reduction in future streamflows, the integrated assessment of water security using REALM and considering water supply and demand balance, suggest that streamflows and infrastructure will be sufficient to provide water for urban water supply during the wet season, but in the dry season allocation problems may prevail, particularly when other water needs such as irrigation demands are considered. More importantly, the model shows that for all future climate scenarios the planned infrastructure upgrades and future demand management are likely to have a much more pronounced impact than climate change.

\section{ACKNOWLEDGEMENTS}


The authors would like to express their appreciation for the support by AusAID-CSIRO Alliance and CSIRO Climate Adaptation Flagship to the Makassar Case Study under the project 'Climate Adaptation through Sustainable Urban Development'. The authors would like to thank the Dr Prasantha Hapuarachchi, Dr Tom Pagano and Dr David Robertson for access and assistance with the SWIFT model, and Dr. Chris Perera with assistance with the REALM model. The assistance of colleagues from University Hasanuddin, JICA and PDAM Makassar in the gathering of background information for the project is also gratefully acknowledged.

\section{REFERENCES}

Bennett, J. C., F. L. N. Ling, D. A. Post, M. R. Grose, S. P. Corney, B. Graham, G. K. Holz, J. J. Katzfey and N. L. Bindoff 2012. High-resolution projections of surface water availability for Tasmania, Australia. Hydrology and Earth System Science 16(5): 1287-1303. DOI: 10.5194/hess-16-1287-2012

BPS, M. 2010. Makassar dalam Angka 2010. Katalog BPS 1102001.7371, Bandan Pusat Statistik Kota Makassar, Makassar, Sulawesi.

Chiew, F., M. Peel, A. Western, V. Singh and D. Frevert 2002. Application and testing of the simple rainfallrunoff model SIMHYD. Mathematical models of small watershed hydrology and applications: 335-367.

Chiew, F. H. S., D. G. C. Kirono, D. M. Kent, A. J. Frost, S. P. Charles, B. Timbal, K. C. Nguyen and G. Fu 2010. Comparison of runoff modelled using rainfall from different downscaling methods for historical and future climates. Journal of Hydrology 387(1-2): 10-23. DOI: 10.1016/j.jhydrol.2010.03.025

CSIRO 2012. The impacts of climate change and urban development on future water security and the adaptation options for Makassar City, Indonesia. A synthesis of findings from Climate Adaptation through Sustainable Urban Development Research Project (SUD).

Duan, Q. Y., V. K. Gupta and S. Sorooshian 1993. Shuffled complex evolution approach for effective and efficient global minimization. Journal of Optimization Theory and Applications 76(3): 501-521. DOI: $10.1007 / \mathrm{bf} 00939380$

Kay, A., H. Davies, V. Bell and R. Jones 2009. Comparison of uncertainty sources for climate change impacts: flood frequency in England. Climatic Change 92(1): 41-63. DOI: 10.1007/s10584-008-9471-4

Leggett, J. A. and J. Logan 2008. Are Carbon Dioxide Emissions Rising More Rapidly Than Expected? In. DTIC Document.

McGregor, J. L. and M. R. Dix 2008. An updated description of the conformal-cubic atmospheric model. High resolution numerical modelling of the atmosphere and ocean.K. Hamilton and W. Ohfuchi (Eds), Springer.

Mitchell, V. G. 2006. Applying integrated urban water management concepts: A review of Australian experience. Environmental Management 37(5): 589-605.

Moore, R. J. 2007. The PDM rainfall-runoff model. Hydrology and Earth System Science 11(1): 483-499. DOI: $10.5194 /$ hess-11-483-2007

Nash, J. E. and J. V. Sutcliffe 1970. River flow forecasting through conceptual models part I - A discussion of principles. Journal of Hydrology 10(3): 282-290. DOI: 10.1016/0022-1694(70)90255-6

Nihon Suido Consultants Co. LTD., Nippon Koei Co. LTD and KRI International Corp. 2011. The preparatory survey on the Makassar water supply development project (Stage II) in the Republic of Indonesia. Interim Report, Volume I, Main Report. The Republic of Indonesia, Japan International Cooperation Agency, Ministry of Public Works, South Sulawesi Province, PDAM Makassar, PDAM Gowa, PDAM Maros and PDAM Takalar.

Pagano, T., H. Hapuarachchi, D. Shrestha, P. Ward, J. Anticev and Q. Wang (2012). Hydrologic modelling with SWIFT to support realtime short-term streamflow forecasting. Series Editor. Series Hydrologic modelling with SWIFT to support realtime short-term streamflow forecasting. Science Symposium Proceedings, 1-5 August 2011, Melbourne: 99-104.pp.

Paton, F. L., H. R. Maier and G. C. Dandy 2013. Relative magnitudes of sources of uncertainty in assessing climate change impacts on water supply security for the southern Adelaide water supply system. Water Resources Research 49(3): 1643-1667. DOI: 10.1002/wrcr.20153

Perera, B. and B. James 2003. A generalised water supply simulation computer software package. Hydrology Journal, Institution of Engineers (India) 26: 67-83.

Selintung, M. 2000. Interactions of environmental assessment and coastal zone management: Bili-Bili dam case. Science and Technology 2(1): 38-50.

Thoms, M. and F. Sheldon 2000. Water resource development and hydrological change in a large dryland river: the Barwon-Darling River, Australia. Journal of Hydrology 228(1): 10-21.

Tjandraatmadja, G., L. E. Neumann, F. Lipkin, S. Maheepala and D. G. C. Kirono 2012. Modelling water supply and demand for Makassar City, CSIRO, Australia.

Yates, D., J. Sieber, D. Purkey and A. Huber-Lee 2005. WEAP21-A Demand-, Priority-, and PreferenceDriven Water Planning Model: Part 1: Model Characteristics. Water International 30(4): 487-500. 